\title{
INDICATIVOS PARA PENSAR UMA PROPOSTA PARA A EDUCAÇÃO FÍSICA ESCOLAR: DA ELABORAÇÃO AO DIÁLOGO COM A INTERVENÇÃO
}

\author{
INDICATIONS TO THINK A PROPOSAL FOR SCHOOL PHYSICAL EDUCATION: \\ FROM PREPARING TO DIALOGUE THROUGH INTERVENTION
}

INDICATIVOS PARA PENSAR UNA PROPUESTA PARA LA EDUCACIÓN FÍSICA
ESCOLAR: DE LA ELABORACIÓN AL DIÁLOGO CON LA INTERVENCIÓN

Luciano De Almeida ${ }^{1}$

Paulo Evaldo Fensterseifer ${ }^{2}$

Resumo

O presente artigo tem por objetivo construir um aporte teórico que nos auxilie na problematização das questões relacionadas ao conhecimento na Educação Física escolar e também a potencializar os sujeitos na elaboração de projetos ou propostas para o nosso campo de tematização, uma vez que a falta destas tem nos limitado à adoção de algumas modalidades esportivas e a outras atividades referenciadas no lazer. A construção/elaboração/adoção de uma proposta para a Educação Física escolar apresenta-se como um dos caminhos possíveis para redimensionar nossa tarefa educativa (assumindo nosso protagonismo), considerando o caráter de uma disciplina escolar, os diferentes tipos de conhecimento com as manifestações relacionadas ao corpo, ao se-movimentar, ao campo do lazer e à promoção da saúde; além de potencializar nossos alunos a estabelecerem uma relação mais lúcida com o mundo e a construirem suas próprias interpretações para os problemas do seu tempo.

Palavras-chave: educação Física escolar; se-movimentar; cultura corporal de movimento

This article aims to build a theoretical contribution to help us problematize issues related to knowledge in school Physical Education, and also to empower the subjects about the elaboration of projects or proposals for our field of thematization since their lack has limited the adoption of some sports modalities and other leisure activities. The construction/elaboration/adoption of a proposal for school Physical Education is one of the possible ways to re-dimension our educational task-assuming our leadership position within the process-,considering the nature of a school subject, the different types of knowledge related to body manifestations, movement, leisure, and health promotion; and to empower our students to establish a clearer relationship with the world and to construct their interpretations for the problems of their time.

Keywords: school physical education; moving; body culture of movement

1 Doutor em Educação nas Ciências.Instituto Federal de Farroupilha, Brasil. Correo electrónico: luciano.almeida@iffarroupilha.edu.br

2 Doutor em Educação. Universidad Unijui, Brasil. Correo electrónico: fenster@unijui.edu.br 


\section{Resumen}

El presente artículo tiene por objetivo construir un aporte teórico que nos ayude en la problematización de las cuestiones relacionadas con el conocimiento en la educación física escolar y también nos permita fortalecer a los sujetos en la elaboración de proyectos o propuestas para nuestro campo de tematización, una vez que la falta de estas nos limita a la adopción de algunas modalidades deportivas y otras actividades referenciadas en el ocio. La construcción, elaboración y adopción de una propuesta para la educación física escolar se presenta como uno de los caminos posibles para redimensionar nuestra tarea educativa (asumiendo nuestro protagonismo), considerando el carácter de una disciplina escolar, los diferentes tipos de conocimiento con las manifestaciones relacionadas con el cuerpo, el movimiento, el campo del ocio y la promoción de la salud; además de empoderar a nuestros alumnos para que establezcan una relación más lúcida con el mundo y construyan sus propias interpretaciones para los problemas de su tiempo.

Palabras clave: educación física escolar; movimiento; cultura corporal de movimiento

Fecha de recepción: 13 de marzo de 2018

Fecha de aprobación: 27 de octubre de 2018

Para citar este artículo:

De Almeida, L., y Fensterseifer, P. (2018). Indicativos para pensar una propuesta para la educación física escolar: de la elaboración al diálogo con la intervención. Lúdica Pedagógica, 28, 55-67. 


\section{INTRODUÇÃO}

A Educação Física passou por diferentes mudanças em seus discursos legitimatórios e em seus marcos legais (o que não necessariamente encontrou acolhida no contexto escolar), alcançando o status de disciplina, o que exige dela uma responsabilidade de passar de mero espaço de atividades ("exercitar-se para") para um campo de tematização capaz de tratar pedagogicamente os temas relacionados à cultura corporal de movimento e produzir um saber acerca desses temas, diferentemente de outras instituições sociais ${ }^{3}$.

Com essa "nova" configuração veio a responsabilidade de construirmos novas práticas e atribuirmos novos sentidos para as mesmas, assumindo nossa condição de protagonistas na elaboração de proposições capazes de redimensionar o hiato entre o "não mais e o ainda não"4 na Educação Física escolar, conservando e transmitindo para as novas gerações (a partir das especificidades de nosso campo de tematização), o acervo cultural produzido pela humanidade em torno do se-movimentar e das práticas corporais que se configuraram em saberes sistematizados (materializados nos currículos e conteúdos escolares), para que essas sintam-se em casa no mundo e possam construir referenciais para analisar, praticar e compreender as diferentes manifestações da cultura corporal de movimento em benefício de condições de vida mais desejáveis.

Assumindo essa responsabilidade, adotamos uma postura crítica pela chave de leitura da hermenêutica ${ }^{5}$, uma vez que esta nos permite reconhecer o caráter provisório de nossas proposições, em um

3 Visto que a Atividade Física, o esporte, a socialização, etc. não estão na dependência da Educação Física Escolar, embora possam ser por ela mobilizados e terem seus sentidos alterados.

4 A expressão utilizada por Gonzalez e Fensterseifer (2010), "entre o não mais e o ainda não", reflete um dos quadros da Educação Física escolar na contemporaneidade, uma vez que nosso campo de tematização está entre uma prática que não se acredita mais e outra que temos dificuldade de pensar, algo que exige o protagonismo dos envolvidos.

5 Embora aparentemente ambígua esta posição, visto referenciar-se em duas tradições aparentemente contrárias (crítica e hermenêutica), revela a compreensão de que o exercício da crítica é não só compatível com o reconhecimento da historicidade da condição humana e sua imbricação com a tradição, como nos lembra a hermenêutica, como é, pelo reconhecimento deste pertencimento, potencializada, trazendo desdobramentos para nossas produções materiais e simbólicas. mundo cambiante a ser problematizado constantemente, que desconfia de uma perspectiva crítica ${ }^{6}$ que julga necessário apresentar de vez (como fundamento metafísico) o acesso às "coisas mesmas"7. Essa desconfiança permite-nos, também, eleger critérios de razoabilidade para nos posicionarmos frente ao que nos vem ao encontro e estabelecermos os acordos necessários para o entendimento entre nós humanos, algo que potencializa a continuidade do exercício da crítica (González e Fensterseifer, 2014).

Nesse sentido, apresentamos neste texto algumas possibilidades que possam nos auxiliar a problematizar as questões relacionadas ao conhecimento em nosso campo de tematização, aos diferentes tipos de saberes e dimensões, e também a potencializar os sujeitos na elaboração de projetos ou propostas para a Educação Física escolar para além dos interesses privados ou projetos particulares, sem a pretensão ou ilusão de que possamos controlar o sentido dessas proposições, mas "apostando que a explicitação da sua pluralidade permite-nos uma convivência dialógica compatível com um modo de sociabilidade democrático e republicano" (González e Fensterseifer, 2014, p. 25).

\section{ALGUNS CRITÉRIOS PARA A ELABORAÇÃO DE UMA PROPOSTA DE INTERVENÇÃO}

Com base em González e Fensterseifer (2010), destacamos dois elementos para pensar na elaboração de uma proposta para a Educação Física na escola o primeiro estaria relacionado à ideia de identificar o campo de conhecimentos particulares que justificariam sua pertinência como disciplina escolar "com responsabilidades específicas em um projeto educacional que potencialize uma relação mais lúcida com o mundo" (p. 13); o segundo diz respeito aos conhe-

6 Para González e Fensterseifer (2014, p. 24-25), "Objetividade, Verdade, Transparência, Razão... são inibidoras da crítica quando a promovem com demasiadas expectativas, e a promovem quando assumem sua provisoriedade, pois assim mantêm aberta a possibilidade da continuidade deste exercício".

7 Algo só permitido aos deuses que estão em um lugar acima das relações mundanas (podem analisar o mundo de fora).

8 Nossa intenção não é a de construir uma proposta ou projeto para a Educação Física escolar, mas pensar nos desdobramentos que a adoção de um referencial fenomenológico-hermenêutico pode trazer para a elaboração de projetos ou propostas para a Educação Física escolar contextualizadas (que não dispensa o protagonismo dos envolvidos). 
cimentos culturais, dos quais a Educação Física se apropria (se ocupa), e que merecem ser tratados diferentemente de outros espaços sociais, atendendo as características do universo escolar e as especificidades do campo de tematização (enquanto disciplina escolar), "e não apenas um espaço para reproduzir/ imitar o que acontece fora dela" (p. 13).

O campo de conhecimento da Educação Física escolar desdobra-se, segundo os autores, em três dimensões que, se bem vinculadas, constituiriam tipos diferentes de conhecimentos que contemplariam as especificidades desse campo de tematização enquanto disciplina escolar. A primeira dimensão refere-se às possibilidades do se-movimentar ${ }^{9}$ dos seres humanos, que estaria vinculada à ideia de oportunizar (particularmente a criança) a apropriação das diferentes manifestações da cultura corporal de movimento (em especial pela-na experiência do seu se-movimentar) para descobrir-ampliar-aprender outras possibilidades de movimento "oferecidas culturalmente pelo seu entorno social imediato, contribuindo, dessa maneira, para a construção de novas referências sobre seu próprio corpo, potencialidades para se-movimentar e interagir com o ambiente" (González e Fensterseifer, 2010, p. 14).

Sem a pretensão de uma retomada exaustiva sobre as possibilidades do se-movimentar, destacamos pelo menos duas perspectivas para o mesmo na Educação Física escolar: a primeira estaria mais vinculada à ideia de "exploração" através da experiência (principalmente corporal) de movimentos para possibilitar (particularmente) às crianças a chance de se apropriarem de diferentes jogos, brincadeiras, atividades expressivas, etc., o que as potencializaria a perceberem as possibilidades e limites do próprio corpo (conhecimento do corpo) e a se relacionarem com o ambiente físico (material) e social (com o outro) ${ }^{10}$; a segunda perspectiva estaria associada à apropria-

9 Para recuperar ou aprofundar a questão em torno do se-movimentar, buscar em: Kunz, E. (2000) Transformação didático-pedagógica do esporte. 4. ed. ljuí: Ed. Unijuí; e também: Educação Física: ensino e mudanças. 2. ed. ljuí: Unijuí, 2001.

10 Ao propormos essa primeira perspectiva do se-movimentar para a construção dessa dimensão do conhecimento, centrada (principalmente) na experiência de movimento, não estamos propondo a incorporação de vivências puras (aculturais), uma vez que não existem experiências que possam acontecer no vazio social, tendo em vista que sempre estarão encharcadas ção das diferentes manifestações da cultura corporal de movimento (corporal e conceitualmente), permitindo aos alunos uma relação mais lúcida (em termos de complexidade e criticidade) com a estrutura e a dinâmica das práticas corporais (sistematizadas) e as significações a elas atribuídas (González e Fensterseifer, 2010).

Acreditamos que essa primeira perspectiva do se-movimentar estaria mais direcionada às séries iniciais do ensino fundamental ${ }^{11}$, uma vez que poderia (deveria) partir das experiências vividas pelas crianças em seu contexto social imediato e oferecer a elas a oportunidade de exploração de novas possibilidades de se-movimentar, algo que potencializa que o conhecimento seja atualizado quando estas "são desafiadas a realizarem movimentos que se entendem possíveis, mas também desejáveis" (González e Fensterseifer, 2010, p. 14), ou seja, sem esquecer as intencionalidades pedagógicas que movem os afazeres da escola ${ }^{12}$. Entendemos que uma das possibilidades (mas não única) para a abordagem dessa perspectiva do se-movimentar encontra-se na concepção de aulas abertas à experiência, proposta por Hildebrandt-Stramann (2001), que sugere a exploração de diferentes situações de movimento pela resolução (individual e coletiva) de problemas propostos nessas situações, algo que permitiria aos alunos o reconhecimento de outras possibilidades de se-movimentar, sem estar única e exclusivamente subordinadas ao esporte, potencializando-as a reinventá-lo (atribuindo-lhe outros sentidos possíveis).

de valores e formas de entender o mundo (González e Fensterseifer, 2010)

11 Os referenciais curriculares (do estado Rio Grande do Sul e de São Paulo, por exemplo) orientam-se para a organização-sistematização de diretrizes curriculares para a Educação Física tendo como público-alvo os alunos das séries finais do ensino fundamental e ensino médio, deixando em aberto a construçãoelaboração de algumas referências para pensar o ensino fundamental (séries iniciais). A Proposta Curricular do Estado de São Paulo faz uma breve referência às experiências anteriores dos alunos, como por exemplo nos jogos coletivos com regras simples, que deverão ter um nível de complexidade maior, tornando as tarefas mais desafiadoras às crianças e jovens das séries finais do ensino fundamental, uma vez que entrarão em contato com os códigos da cultura esportiva (São Paulo, 2008).

12 Instituição que possui, como um de seus objetivos: estimular, "provocar e facilitar a reconstrução dos conhecimentos, atitudes e formas de conduta que os alunos e alunas assimilam direta e acriticamente nas práticas sociais de sua vida anterior e paralela à escola" (Sacristán e Gómez, 1998, p. 25). 
Outra possibilidade para essa perspectiva do se-movimentar estaria relacionada à ideia de construção de referenciais curriculares, também para as séries iniciais, o que permitiria a sistematização do conhecimento em nosso campo de tematização já nas mais tenras idades. Nesse sentido, encontramos uma proposta muito interessante no trabalho de González e Schwengber (2012), os quais propõem uma sistematização do conhecimento a partir de quatro eixos estruturadores para as possibilidades do se-movimentar: a) conhecimento do próprio corpo e a percepção do entorno; b) habilidades motoras básicas; c) expressão e comunicação pelo gesto e movimento; d) formas de jogar. Estes eixos estruturadores estariam organizados principalmente nas experiências de movimento, considerando as práticas corporais como meios para a exploração (no sentido de experenciar) do "corpo e as possibilidades de ação dos sujeitos e, ainda, objetos culturais a serem estruturados, conhecidos e aprendidos" ${ }^{13}$ (González e Schwengber, 2012, p. 24).

A segunda perspectiva que propomos para o se-movimentar "comporta" a experiência que, não necessariamente, é "referenciada" na experiência de movimentos, como na primeira perspectiva, uma vez que "reúne tanto os saberes produzidos pela experimentação da prática corporal, como os conhecimentos conceituais sobre a estrutura e dinâmica desta e os significados sociais a ela atribuídos" (González e Fensterseifer, 2010, p. 16). Isso não quer dizer que a primeira perspectiva do se-movimentar está voltada para o acúmulo de vivências (no sentido de simples fruição ${ }^{14}$ ), mas que há a necessidade de proporcionar aos alunos (de forma mais sistemática) o acesso ao acervo cultural produzido pela humanidade para que eles possam se situar no mundo e participarem

13 Para um aprofundamento desse referencial, ver em: González e Schwengber (2012).

14 Chamamos a atenção para o fato de que estamos dando uma conotação negativa para o termo "fruição" quando este apresenta um fim em si mesmo, sem uma intencionalidade pedagógica. Por outro lado, a expressão "fruição", quando associada à intencionalidade de uma prática pedagógica (como na Educação Física escolar, por exemplo), pode associar-se (também) à ideia de experiência como erlebnis, que indica uma experiência pré-reflexiva, imediata, pessoal e "intransferível" e possui um sentido marcadamente positivo, uma vez que pode ser considerada o início da "viagem" (experiência humana como erfahrung) e não um aglomerado de vivências sem sentido algum (Jay, 2009). de sua construção. 0 fio condutor dessas duas perspectivas para o se-movimentar encontra-se na relação de diálogo do sujeito que se-movimenta com seu mundo (material e social), para que possa apropriar-se de diferentes saberes e ampliar sua compreensão do mundo.

Essa segunda perspectiva para o se-movimentar vincula-se à segunda dimensão do conhecimento proposta por González e Fensterseifer (2010), que diz respeito às práticas corporais sistematizadas vinculadas ao campo do lazer, o cuidado do corpo e à promoção da saúde que foram-são incorporadas pela Educação Física (enquanto campo de tematização) e constituem-se em práticas sociais que possuem alguns elementos em comum: “a) o movimento corporal como elemento essencial; b) uma organização interna (de maior ou menor grau) pautada por um lógica específica; e c) serem produtos culturais vinculados com o lazer/entretenimento e/ou o cuidado do corpo e a saúde" (p. 15). Esses elementos constituem o universo das práticas corporais que compõem o campo de estudo da Educação Física, materializados nos temas-conteúdos: esportes, jogos, lutas, danças, jogos motores, exercícios físicos, atividades aquáticas, acrobacias, práticas corporais de aventura na natureza, práticas corporais introspectivas.

Nessa dimensão, destacamos a pluralidade de manifestações da cultura corporal de movimento que foram incorporadas pela Educação Física durante a sua constituição e se configuraram em práticas corporais sistematizadas (como produções humanas) e que, entendemos, merecem ser conservadas e transmitidas para as novas gerações como parte integrante de nossa herança cultural. Outro fator que destacamos refere-se ao tratamento dado a esses temas, uma vez que produz diferentes tipos de saberes (corporais, conceituais, éticos, estéticos e expressivos).

Aqui, nos deparamos com um dos paradoxos de nosso campo de tematização, uma vez que temos de lidar com tipos de conhecimentos que não podem ser alcançados sem a experiência com o se-movimentar, e outros que não se reduzem aos saberes conceituais, mas que podemos recorrer a eles para construirmos um entendimento compartilhado, pois seus modos de ser se manifestam em diferentes formas de linguagem. 
Nessa relação paradoxal, destacamos também a tensão permanente no tratamento das questões relacionadas ao corpo e seus desdobramentos. Se, por um lado, defendemos a revisão do projeto moderno dualista (cisão de corpo e mente), em que o corpo está subordinado ao pensamento (como simples instrumento), produzindo discursos sobre o mesmo (descrição científica), temos que ficar atentos para não inverter essa lógica e superdimensionar a nossa relação com o corpo, uma vez que poderia nos levar (tem levado) a buscar o prazer (individual) imediato (com as práticas corporais) a "custo zero", livre de qualquer normatividade ou coerção ${ }^{15}$. Algo que vem de encontro aos propósitos institucionais de uma escola que tem como uma de suas tarefas oferecer "aos seus egressos as competências necessárias a uma participação 'qualificada' no espaço público" (Brayner, 2008, p. 15) e, para isso, faz-se necessário reconhecer que não há aprendizagem sem esforço, sem acordos razoáveis entre nós (humanos), mesmo que esses acordos não atendam a nossos interesses particulares imediatos.

Por fim, a terceira dimensão do conhecimento proposta por González e Fensterseifer (2010) incluiria as estruturas e representações sociais que atravessam esse universo (composta pelos conceitos) que nos permitem refletir sobre a origem e transformação das representações e práticas sociais que estariam relacionadas "com as atividades corporais de tempo livre, o cuidado e a educação do corpo, seus vínculos com a organização da vida coletiva e individual, bem como os agentes sociais envolvidos em sua produção (estado, mercado, mídia, instituições esportivas [...])" (p. 16).

Essas dimensões do conhecimento, propostas pelos autores, remetem-nos a pensar a complexidade e ambivalência no tratamento aos diferentes tipos de saberes produzidos em nosso campo de tematização,

15 Essa relação, segundo Costa (1999) referenciado por Illich, promove uma idolatria do corpo e das sensações e é contrária à liberdade humana, uma vez que "a obsessão em sobreviver e evitar todo sofrimento a qualquer custo redundou em alienação do mundo e de si mesmo. Não temos, é claro, por que sofrer desnecessariamente ou abrir mão de ser felizes. Mas, quando a felicidade se torna mero interesse pela sobrevida e pela busca incessante de prazer, o resultado é a perene insatisfação consigo, a indiferença para com o outro e o esvaziamento do próprio sentido da vida. O bem-estar do corpo se converteu no mal-estar da ética" (p. 41). sem eleger (ou hierarquizar) uma dimensão primordial, mas manter uma tensão entre esses saberes para potencializar a compreensão acerca dos limites e possibilidades do conhecimento em Educação Física, como produção humana.

Nesse sentido, recorremos ao Referencial Curricular de Educação Física do estado do Rio Grande do $\mathrm{Sul}^{16}$, para reconhecer a tensão permanente entre as diferentes formas de conhecer em nosso campo de tematização no intuito de potencializar os sujeitos a ampliarem sua (nossa) compreensão de mundo, atendendo aos propósitos da escola.

Esse referencial curricular constitui-se, segundo González e Fraga (2009), em um ponto de partida para explicitar aqueles saberes considerados fundamentais em nosso campo de tematização, para auxiliar na organização, planejamento e implantação "de propostas de ensino que favoreçam o processo de apropriação, problematização e uso criativo por parte dos alunos" (González e Fraga, 2009, p. 114), do conjunto de competências ${ }^{17}$ e conteúdos necessários para uma relação mais lúcida com o mundo. 0 referencial curricular do Rs foi elaborado e organizado a partir de temas estruturadores divididos em dois conjuntos:

O primeiro está organizado com base nas práticas tradicionalmente consideradas como objeto de estudo da Educação Física: esporte, ginástica, jogo motor, lutas, práticas corporais expressivas, práticas corporais junto à natureza e atividades aquáticas. 0 segundo conjunto está organizado com base no estudo das representações sociais que constituem a cultura de movimento e afetam a educação

16 Também nos apropriaremos das reflexões de González e Fraga (2012), em sua obra Afazeres da Educação Física na escola: planejar, ensinar, partilhar - publicada pela Editora Edelbra.

17 Para os autores, a noção de competência aqui empregada diz respeito à "capacidade, hipotética e aprendida, de mobilizar, integrar e harmonizar recursos, como: informações, saberes, atitudes, conhecimentos teóricos ou metodológicos, esquemas motores, de percepção, avaliação para o sujeito tomar decisões e atuar frente a situações complexas que acabam surgindo no dia-a-dia" (p. 114), a partir das especificidades de cada componente curricular, mas não como conjunto de meios racionais e instrumentais (considerando apenas os aspectos técnicos), que nos permitiriam atingir qualquer objetivo (como sujeitos isolados), uma vez que só fazem sentido se pensadas na relação com o Outro (Brayner, 2008). Pensadas dessa forma, as competências nos auxiliariam a construir critérios de razoabilidade para o entendimento entre nós humanos, para além dos interesses (exclusivamente) particulares. 
dos corpos de um modo geral; portanto, sem estar necessariamente vinculada a uma prática corporal específica. (González e Fraga, 2009, p. 118).

Esse referencial nos apresenta um mapa conceitual para a abordagem das relações de ensino e aprendizagem na Educação Física ao longo dos anos escolares em termos de criticidade e complexidade. Tomamos como exemplo o tema esporte, tendo em vista que é um dos temas mais "trabalhados" nas aulas de Educação Física (senão o único). Com esse referencial, só a abordagem dos esportes nos permitiria traçar objetivos para todos os anos escolares ${ }^{18}$.

Geralmente o ensino dos esportes está centrado na prática de algumas modalidades em forma de lazer (no sentido de simples fruição) ou de treinamento. Essa forma de tratamento de um tema-conteúdo na Educação Física não contempla as especificidades da escola, uma vez que esta é "um lugar em que é possível defender e construir formas de olhar e sentir o mundo diferente daquelas que permitem outras instituições sociais" (González e Fensterseifer, 2009, p. 21).

Nesse sentido, González e Fraga (2009) elaboram uma "categorização" que permite dar um tratamento diferenciado ao esporte, a qual se divide em "saberes corporais" e "saberes conceituais". 0 primeiro necessita ser experienciado pelo sujeito, pelo seu se-movimentar, uma vez que promove a apropriação de um conhecimento "encarnado"; sem ele não é possível sentir a experiência nos acontecer ou nos tocar ${ }^{19}$

18 Para exemplificar essa afirmação, recorremos à classificação dos esportes elaborada por González (2006), que divide os esportes em categorias: a relação de cooperação (individual ou coletiva) e oposição (com ou sem interação direta com o adversário); lógica de comparação de desempenho e princípios táticos; as características do ambiente físico em que a prática se realiza. Resumidamente, poderíamos citar os esportes com interação com o adversário: esportes de invasão; esportes de campo e taco; esportes de combate ou lutas; esportes de quadra dividida ou muro. Esportes sem interação com o adversário: esportes de marca ou rendimento; esportes de precisão ou alvo; esportes estéticos ou técnico-combinatórios.

19 Se recuperarmos a ideia da experiência como viagem, e a Educação Física como possibilidade de um dos roteiros para perceber o mundo e perceber-nos, poderíamos estabelecer uma nova analogia, como ocorre na oportunidade de conhecer um novo lugar, com paisagens belíssimas e um rico patrimônio cultural peculiar de uma região. Esse lugar poderia ser registrado em filmagens, fotos, descrições, mas não consegue substituir a experiência do sujeito com as diferentes situações que se depara no lugar, pois produz um tipo de conhecer que "se sente na pele".
(Bondía, 2002); com ele podemos perceber nossos próprios limites na realização de determinado movimento, bem como as possibilidades de diferentes formas de realizá-lo; dito de outro modo, necessitamos da credencial de vivência própria (Gadamer, 2008). 0 segundo estaria relacionado àqueles saberes que nos proporcionam fazer uma "leitura" do esporte e nos fornecer pistas para entender suas mudanças em função de uma diversidade de significados que o compõe $\mathrm{e}^{20}$.

Os "saberes corporais" são apresentados por González e Fraga (2009) em subeixos: "saber praticar" e "praticar para conhecer". Como há uma diversidade de temas a serem abordados nas aulas de Educação Física (e o esporte é um deles), essa divisão nos auxilia a organizar o tempo curricular (carga horária) para a abordagem de cada prática corporal. Por exemplo, na abordagem dos esportes de invasão (futsal ou futebol de campo) o tempo destinado a essas modalidades deveria ser maior, uma vez que se enquadram no subeixo "saber praticar". Já no subeixo "praticar para conhecer" destina-se um tempo menor para oportunizar aos alunos a chance de experienciar uma modalidade pouco conhecida, como um esporte de campo e taco (críquete), por exemplo. Um dos critérios apontado pelos autores para essa distribuição refere-se ao potencial de exploração de determinados esportes (práticas corporais) no tempo livre dos alunos, considerando o contexto de determinadas comunidades escolares, porém com o cuidado para não se pautar somente pela ideia de reprodução da dinâmica da cultura corporal de movimento local, "mas também pela ideia de diversificação das práticas de lazer, procurando potencializar a democratização do envolvimento com os esportes, exercícios físicos, expressão corporal, etc. dos diferentes segmentos da sociedade" (González e Fraga, 2012, p. 52).

Da mesma forma, os "saberes conceituais" são apresentados em dois subeixos: "conhecimento técnico" e "conhecimento crítico". o primeiro caracteriza-

20 Aqui podemos citar as mudanças nas regras de voleibol, como por exemplo: "Entender que as mudanças nas regras do vôlei se deram por razões técnicas e interesses econômicos é um tipo de saber que possibilita desenvolver a competência de compreender a diversidade de significados e a inserção desta prática em distintas épocas e contextos socioculturais" (González e Fraga, 2009, p. 119). 
-se pela abordagem de conceitos necessários para o entendimento sobre o "funcionamento" do esporte (práticas corporais) em uma dimensão operacional. Nessa lógica, as práticas corporais podem ser estudadas, por exemplo: "Como se classificam os esportes de acordo com os princípios táticos, o efeito de determinado exercício físico no desenvolvimento de uma capacidade motora" (González e Fraga, 2009, p. 121). Por sua vez, o subeixo "conhecimento crítico" aborda a inserção do esporte (práticas corporais) em diversos contextos socioculturais. Esse subeixo permite aos alunos uma análise das manifestações da cultura corporal de movimento "em relação às dimensões éticas e estéticas, à época e à sociedade que as gerou, às razões da sua produção e transformação, à vinculação local, nacional e global” (p. 122). Também estimula um processo de reflexão "sobre as possibilidades que os alunos têm (ou não) de acessar uma determinada prática no lugar onde moram, os recursos disponíveis (públicos e privados) para tal, os agentes envolvidos com o seu desenvolvimento, entre outros aspectos" (p. 122).

Apesar desse referencial ser apresentado de maneira compartimentada, os autores chamam a atenção de que seria um equívoco pensar que as competências e os conteúdos pudessem ser ensinados de forma separada. Foram apresentados, assim, para possibilitar uma leitura dos desdobramentos da proposta para um melhor entendimento. Segundo estes, há a necessidade de articulação das competências e conteúdos nos diferentes eixos e subeixos "do tema estruturador a ser estudado" (González e Fraga, 2009, p. 22).

Esse referencial curricular nos oferece um ponto de partida para construirmos nossos próprios projetos de Educação Física para o contexto específico em que atuamos (sem esquecer nosso protagonismo). Ele se articula com as dimensões propostas por González e Fensterseifer (2010) e contempla os diferentes tipos de conhecimento com as manifestações culturais relacionadas ao corpo, ao se-movimentar, ao campo do lazer e à promoção da saúde e à intencionalidade pedagógica em uma disciplina escolar.

\section{UM DIÁLOGO COM A INTERVENÇÃO..}

Para iniciar esse diálogo é preciso reconhecer que a falta de uma proposição para a Educação Física na escola, materializada em uma organização curricular, pode levar-nos (tem levado) a reduzir nossas aulas à incorporação de algumas modalidades esportivas e a outras atividades referenciadas no lazer. Da mesma forma, acreditamos que a adoção de um referencial curricular, sem considerar as características do contexto escolar, também não é desejável. Essa afirmação se sustenta no fato de que a adoção de um referencial curricular deve considerar o contexto que envolve a escola (projeto político-pedagógico, planos de estudo da disciplina, realidade dos alunos - o que sabem?), para que possa ter a chance de ser experienciado e reelaborado na e para a realidade em que a proposta ou projeto será (está sendo) desenvolvido.

A título de exemplo, podemos pensar na adoção do referencial curricular do RS (González e Fraga, 2009) para os alunos do primeiro ano do ensino médio de uma escola pública ${ }^{21}$. 0 referencial apresenta no tema estruturador esporte, no eixo "saberes corporais" e no subeixo esportes "para saber praticar" como competência para o primeiro ano "usar elementos técnico-táticos avançados, combinações táticas elementares e sistema de jogo básicos no(s) esporte(s) de invasão escolhido(s)" (González e Fraga, 2009, p. 132). Como pensar na transposição ou "aplicação" desse referencial para nossos alunos, se em diagnóstico realizado com os mesmos a grande maioria não consegue "usar de forma proficiente elementos técnico-táticos básicos do(s) esporte(s) de invasão escolhido(s)" (idem, p. 130), competência do eixo "saberes corporais" e subeixo esportes "para saber praticar" para alunos do $5^{\circ}$ e $6^{\circ}$ anos do ensino fundamental ${ }^{22}$ ?

21 No decorrer deste texto, um dos autores trará elementos de sua ação interventiva para o diálogo

22 Queremos deixar claro, aqui, que não estamos fazendo uma crítica ao referencial curricular do RS, que foi muito bem pensado, estruturado e elaborado com um nível de sistematização que contempla as séries finais do ensino fundamental e ensino médio (em termos de criticidade e complexidade). Queremos chamar a atenção para as limitações de aprendizagem quando um referencial organizado e estruturado desde o ensino fundamental não é adotado. Nos diagnósticos realizados com nossos alunos, percebemos que vários deles tiveram contato com duas ou três modalidades esportivas (no máximo) e encontram-se num nível baixo de proficiência neste tema estruturador. Acreditamos ser possível dizer que, em termos de "saberes corporais", eles tiveram mais "vivências" de atividades esportivas no plano de esportes "para conhecer" do que em esportes "para saber praticar", mesmo naquelas modalidades de seu entorno imediato (como é o caso do futsal e do futebol de campo). Cabe destacar aqui, também, que estamos de acordo com González e Fraga (2009, p. 114), quando estes afirmam que o referencial é "um ponto de apoio, e não um texto substituto, ao processo de 
Recorrendo a Gadamer (2008), podemos esboçar um entendimento acerca dessa questão, tendo em vista que a experiência não pode ser conhecida em uma universalidade prévia, o que impõe limites a qualquer tipo de "aplicação" sem um diagnóstico prévio (do contexto), e que a experiência só se atualiza nas observações (vivências) individuais, tanto dos alunos (no contato com os temas) quanto do professor (na intervenção). A credencial de vivência própria permite uma leitura da situação, seja nas limitações dos alunos que não conseguem realizar determinada atividade ou do professor no planejamento de suas aulas.

Pensando nisso, passamos a relatar (resumidamente) uma Unidade Didática (chamada apenas de esportes de invasão ${ }^{23}$ ) realizada com os alunos de ensino médio no ano de 2014, tentando articulá-la com os referenciais deste estudo ${ }^{24}$. Essa unidade foi pensada no sentido de contemplar as dimensões do "conhecer" na Educação Física escolar ${ }^{25}$ que podem ser abordadas nos "saberes corporais" (esportes "para saber praticar" e esportes "para conhecer") e nos "saberes conceituais" ("conhecimento técnico" e "conhecimento crítico"), com base nos trabalhos de González e Fraga (2009; 2012). No eixo "saberes corporais", subeixo esportes "para saber praticar",

elaboração dos planos de estudo de cada instituição. Estes últimos precisam ter a 'cara' da escola, portanto, devem ser feitos por quem vive o dia-a-dia, pois é lá que se tece um currículo”.

23 Os esportes de invasão são caracterizados como aqueles que têm por objetivo invadir o terreno adversário para marcar pontos ou gols e, ao mesmo tempo, defender a sua meta (área) (González, 2006).

24 É importante destacar que, anteriormente à abordagem dessa Unidade Didática, realizamos um diagnóstico com os alunos, na tentativa de identificar o "que já sabiam" em relação às manifestações da cultura corporal de movimento (no plano conceitual). Foi possível perceber (como já mencionamos anteriormente) que, na maioria dos casos, a Educação Física reduzia-se à prática de duas ou três modalidades esportivas, nos limites de uma compreensão prévia de algumas regras. A partir de então, apresentamos nosso "mapa de trabalho" e os temas estruturantes que seriam abordados no ano letivo, e uma projeção do que seria abordado nos demais anos do ensino médio, algo que vem ao encontro das proposições de González e Fraga (2009; 2012).

25 Os objetivos e conteúdos desta Unidade Didática foram pensados a partir de um diagnóstico inicial para identificar o nível de aprendizagem dos alunos em relação às três modalidades dos esportes de invasão (futsal, handebol e basquetebol), que foram abordadas nesta unidade, para que pudéssemos avaliar a progressão dos alunos durante as aulas. Para isso, foram utilizados jogos em escala reduzida (4x4), conforme indicação de González e Fraga (2012). elegemos a modalidade de futsal (de acordo com o interesse dos alunos) e propomos a adoção de mais duas modalidades, o handebol e o basquetebol (para ampliar as possibilidades esportivas no tempo de lazer - espaços extraescolares); no que se refere aos esportes "para conhecer", elegemos o rúgbi, modalidade pouco conhecida pelos alunos ${ }^{26}$.

Nos "saberes conceituais", no subeixo "conhecimento técnico" atribuímos, como meta, abordar os princípios operacionais e as regras de ação (princípios táticos) comuns nos esportes de invasão estudados ${ }^{27}$. Já no que tange ao subeixo "conhecimento crítico", propomos aos alunos identificar locais, nas cidades e bairros em que residem, que oportunizem a prática de alguma das modalidades estudadas.

Foi possível perceber, no desenvolvimento dessa Unidade Didática (e de outras que temos realizado), que essas dimensões do conhecer na Educação Física escolar, compreendidas como diferentes formas de linguagem, nos proporcionam uma leitura mais alargada sobre os possíveis desdobramentos dessa relação em nosso campo de tematização. Tomamos como exemplo uma aula em que realizamos um jogo reduzido de um esporte de invasão, em que foram estabelecidos (previamente) objetivos do que era permitido ou não neste jogo e as formas de pontuar (no plano verbal), e os alunos realizaram uma experiência com este tentando alcançar os objetivos propostos pelo seu se-movimentar, estabelecendo com o outro uma comunicação não verbal (no plano corporal). Após determinado período de jogo, fizemos algumas considerações do que estava acontecendo e questionamos os alunos sobre as dificuldades de alcançarem os

26 As escolhas dessas modalidades devem-se por consideração de alguns fatores: a) esportes "para saber praticar" - por apresentarem em sua estrutura funcional princípios comuns de ataque e defesa; por apresentarem regras de ação comuns no que se refere às intenções táticas que podem ser transferidas de uma modalidade para outra (mesmo sabendo que essa transferência pode ser negativa); b) esportes "para conhecer" - também pelos motivos acima, porém destinando um tempo menor para a sua abordagem, tendo em vista as poucas possibilidades de sua realização nos espaços de tempo livre.

27 Como exemplo, podemos citar uma das intenções táticas abordadas na aula, que se refere ao subpapel - atacante com posse de bola que se materializa nas seguintes questões: quando recebe a bola, fica de frente para a meta adversária? Faz uma leitura da situação de jogo antes de passar, conduzir ou finalizar (antes de agir)? Procura jogar com os companheiros? (González e Fraga, 2009; 2012). 
objetivos e como poderíamos resolvê-los. Nesse diálogo os alunos têm a oportunidade de "traduzir" uma dimensão estética (sensível e subjetiva) do que lhe acontece como forma de perceber-se e reconhecer uma dimensão ética (social e intersubjetiva) do que acontece ao Outro; ou, dito de outra forma, do que nos acontece como forma de perceber o entorno ${ }^{28}$ (mundo material e social). Após esse diálogo (reflexão) o jogo volta a ser jogado e, ainda assim, mesmo com as novas referências proporcionadas pela reflexão, devem aceitar o risco das incertezas que as novas situações irão lhe proporcionar (Hermann, 2002), pois aí se revela o caráter de imprevisibilidade da experiência.

28 Como não se trata de um estudo sistemático de análise das falas dos alunos (por não ser o objetivo do estudo), trazemos um trecho de uma experiência realizada em uma aula da Unidade Didática - esportes de invasão, por entender que a mesma nos permite perceber a importância do diálogo como forma de reconhecer elementos relativos às aprendizagens da experiência. Após a realização de um jogo reduzido (adaptado) de handebol $(4 \times 4)$, que tinha por objetivo trocar passes entre os companheiros e invadir a meta adversária com posse de bola, ou receber a bola na área adversária para marcar o gol, paramos o mesmo para uma avaliação. Quais as maiores dificuldades em alcançar o objetivo do jogo? "Ninguém aparece pra receber"; "ficam escondidos atrás dos adversários"; "não passam a bola"; "só dois estão jogando"; "mas tu não consegue nem pegar a bola". Nessas falas é possível perceber dois elementos importantes: um se refere à dificuldade na leitura no jogo (situação), e outro à participação de todos no jogo (colaboração). O que precisamos fazer (melhorar) para alcançar os objetivos do jogo? "Passar a bola e aparecer pra receber"; "abrir espaços"; "criar linha de passe"; "passar a bola pra todos". Aqui fica evidente a dificuldade de "tradução" das intenções táticas do plano conceitual ("teórico") para o plano procedimental ("prático"), tendo em vista que já havíamos abordado em aulas anteriores e retomado várias vezes (em situações posteriores) as regras de ação dos esportes de invasão. Da mesma forma, fica evidente que os alunos percebem a necessidade de colaborar com os colegas, para alcançar os objetivos do jogo e auxiliá-los a superar suas dificuldades, mas que por vezes, mesmo que involuntariamente, não se dão conta que exageram na individualidade (intencionalidades particulares). Essas situações nos permitem enfatizar que a experiência com as diferentes formas de elaboração do conhecimento na Educação Física escolar, manifestas em diferentes formas de linguagem, só se atualizam nas observações (vivências) individuais (Gadamer, 2008), bem como reafirmam a necessidade da credencial de vivência própria nas diferentes situações da aula, algo que proporciona uma experiência estética (insubstituível) para o sujeito que se-movimenta e para a qual não há substituto, e uma experiência ética, pois sempre nos representamos ou representamos algo para alguém (nos relacionamos com o Outro). Essas diferentes situações e diálogos fazem parte de nosso acervo pessoal, e foram registrados em um diário de campo (digital) e em algumas filmagens; cabe destacar a importância desses registros para posteriores análises, bem como as limitações de se registrar todas as aulas.
A imprevisibilidade que ocorre na experiência refere-se ao seu resultado, que não pode ser antecipado (previamente) sem a participação do sujeito (na situação), algo que não pode ser confundido com a falta de uma intencionalidade. Perceber isso pode auxiliar-nos a redimensionar nossa tarefa educativa (relação pedagógica), uma vez que nos permite reconhecer que não temos como conduzir (ou controlar) a experiência do outro, apenas induzi-la (ou propô-la) (Almeida, Fensterseifer e Bracht, 2014). No exemplo aqui relatado, pode-se dizer que induzimos (propomos) uma experiência com a intencionalidade de oportunizar aos alunos uma experiência de movimento enquanto diálogo com seu entorno, para que possam perguntar e responder as questões que surgem na situação, tanto em termos "práticos", em que as soluções "corporais" acontecem na contingência do movimento, quanto em termos "teóricos", para que tenham a possibilidade de refletir sobre as situações do seu próprio se-movimentar (experiência) e tentarem traduzi-las (compartilha-las) com o outro.

Nessa situação de diálogo é possível dizer que há uma mudança significativa em nossa relação pedagógica, uma vez que, além de trabalhar o tema estruturador (do esporte em questão) de forma não diretiva, acontece uma situação aberta de ensino, em que o aluno e o professor podem dialogar e estabelecer uma relação de desafio, no sentido de "fazer do vir ao encontro do outro o campo de aprendizagem intersubjetivo e, por isso mesmo, ético-moral" (Flickinger, 2010, p. 7). Porém, é preciso explicitar que a responsabilidade nessa relação pedagógica continua sendo do professor, o qual, ao induzir experiências de movimento aos alunos, não pode ter a pretensão de controlar as mesmas referenciando-as apenas em estereótipos (de movimento), mas também não pode superdimensionar essa experiência (estética) do sujeito que se-movimenta, pois poderia levar-nos a uma estetização da pedagogia. A intenção aqui é induzir experiências de movimento que possibilitem aos alunos um diálogo com o outro, potencializando-os a solucionarem de maneira autônoma e proficiente o que lhes acontece na contingência das diferentes situações (experiências), e, a posteriori, refletir acerca do acontecido.

Retomando a Unidade Didática no que se refere aos "saberes conceituais", primeiramente é preciso fazer um enfrentamento com os alunos, tendo em vista 
que manifestam um comportamento de oposição em relação a esses saberes, uma vez que construíram um imaginário sobre a Educação Física (durante o ensino fundamental) como uma disciplina essencialmente prática, com pouco (ou nenhum) espaço voltado à reflexão ou à dimensão conceitual ${ }^{29}$. Feito esse movimento inicial de sustentação teórica a respeito dos conteúdos da aprendizagem e as diferentes formas de tratá-lo (abordá-lo), apresentamos no subeixo "conhecimento técnico" uma abordagem comparativa dos princípios operacionais de ataque e defesa comuns nos esportes de invasão estudados, bem como os diferentes subpapeis (princípios táticos) a serem considerados em cada situação de ataque e defesa. Esse "conhecimento técnico" potencializa os alunos a perceberem-se em relação às regras de ação que são necessárias para lograr êxito nas diferentes situações de jogo. Quanto ao "conhecimento crítico", os alunos identificaram, através de um diagnóstico nos bairros e nas cidades onde residem, os locais destinados para a prática de alguma das modalidades estudadas e perceberam a escassez de espaços (públicos) de lazer para a prática esportiva; quando há esses espaços, se restringem a uma monocultura esportiva (futsal) e atendem a uma parcela redu-

29 Ao mesmo passo que os alunos manifestam um comportamento de oposição no momento em que a proposta é apresentada (no início do ano letivo), como podemos perceber em suas falas: "Vamos jogar"; "a aula é só teórica hoje"; "na outra escola que estudei era mais divertido"; "isso é Educação Física?"; no transcorrer do ano letivo vão construindo novos referenciais para compreender as diferentes possibilidades de elaboração do conhecimento nas aulas de Educação Física na escola, que não se reduz à prática de algumas modalidades esportivas. Apesar de não atender algumas expectativas (iniciais), o contato com outras manifestações da cultura corporal de movimento promove uma mudança no comportamento dos alunos em relação às suas expectativas de aprendizagem, uma vez que aguardam a abordagem de algum tema estruturador (em especial) que tenham maior interesse (algo que não acontece de forma hegemônica). O registro de um depoimento de um aluno no final do ano letivo nos dá elementos para entender essa relação: "Em outras escolas nunca aprendi tantos conteúdos na Educação Física como aqui, espero aprender coisas novas no ano que vem e também construir a jangada". Nesse registro fica explícita a expectativa gerada pela ampliação das práticas corporais conhecidas pelos alunos, os quais esperam a continuidade da proposta. A título de curiosidade, o Projeto Jangada (em que os alunos precisam trabalhar em grupo para construir uma "embarcação" que flutue sobre as águas e que suporte no mínimo três integrantes do grupo sobre esta sem "afundar") foi apresentado no início do ano letivo, como "projeto especial" (que foi alocado no tema estruturador "práticas corporais junto à natureza") a ser desenvolvido no $2^{\circ}$ ano do ensino médio e gerou muitas expectativas. zida da comunidade (principalmente masculina), o que potencializou, por um lado, a problematização da questão de gênero nas práticas esportivas extraclasse, e, por outro, a legitimação dos procedimentos da classe relativos ao tema.

Percebemos, com a realização dessa Unidade Didática que tem como tema estruturador o esporte, as diferentes formas de linguagem que compõem o todo de nossa compreensão, e não podem ser reduzidas somente à dimensão verbal da linguagem, em especial quando nos referimos às especificidades de nosso campo de tematização, pois há a necessidade de manter uma tensão permanente entre o verbal e o não verbal (sem sobreposições ou hierarquizações), uma vez que isoladas não conseguiriam dar conta da complexidade das dimensões do conhecer na Educação Física escolar, mesmo porque temos que reconhecer a impossibilidade de alcançarmos o ser (das situações) na sua completude.

Essa compreensão permite-nos reafirmar a validade e dignidade das diferentes dimensões do conhecimento na Educação Física escolar, que se apresentam em diferentes formas de linguagem e que merecem tratamento diferenciado (mas não sobrepostos). Foi possível perceber, no desenvolvimento dessa Unidade Didática e de outras que temos realizado nesses anos de atividade docente, os desdobramentos das dimensões do conhecer na Educação Física escolar que potencializam a "formação de indivíduos dotados de capacidade crítica em condições de agir autonomamente na esfera da cultura corporal de movimento" (González e Fensterseifer, 2010, p. 12). Essa afirmação se sustenta, por exemplo, quando um aluno questiona a monocultura esportiva ou a questão de gênero nos esportes de lazer ("conhecimento crítico"), quando percebe os elementos comuns nos esportes de invasão ("conhecimento técnico"), quando consegue fazer uma bandeja no basquete e fazer a cesta, algo que nunca havia nem tentado ${ }^{30}$

30 Ao final de uma aula da Unidade Didática - esportes de invasão, uma aluna me chamou para agradecer a oportunidade de aprender a jogar basquete (esporte "para saber praticar"). Ela me disse que, em outra escola que estudou, já tinha entrado em contato com a modalidade, mas que as aulas eram destinadas somente ao jogo e à compreensão de algumas regras. "Participava" do jogo, recebendo e efetuando alguns passes, driblando (quicando) a bola (às vezes) e chegando poucas vezes ao ataque (sem muito sucesso). Nesse diálogo com a aluna pude 
("saberes corporais") ou, ainda, quando questiona os colegas sobre a participação de todos nos jogos, e que todos devem ter a mesma chance de aprender, pois se trata de uma aula de Educação Física (esporte escolar) e não de treinamento de uma escolinha (dimensão ética da aprendizagem).

\section{CONSIDERAÇÕES FINAIS}

Acreditamos que o referencial aqui adotado pode nos inspirar (continuar inspirando) a repensarmos nossa tarefa educativa, considerando: o caráter processual do conhecimento (que se dá a cada vez); as demandas que provêm dos marcos legais; a intencionalidade pedagógica em uma disciplina escolar; os diferentes tipos de conhecimento com as manifestações culturais relacionadas ao corpo, ao se-movimentar, ao campo do lazer e à promoção da saúde; e, ainda, a importância de nosso protagonismo na elaboração e reelaboração constante de novas proposições para nosso campo de tematização; afinal, a solução para os problemas depende dos envolvidos (Arendt, 2011).

Em conjunto com as demais "disciplinas" escolares a Educação Física, a partir de suas especificidades, poderia fornecer aos alunos alguns critérios necessários para que possam criticar, entender, praticar, apreciar, analisar o universo da cultura corporal de movimento em benefício de condições de vida mais

perceber sua felicidade ao revelar que, apesar de ter "jogado" vários jogos de basquete, nunca conseguiu fazer uma bandeja e uma cesta em uma partida, e que pela primeira vez conseguiu alcançar esse objetivo. Apesar de parecer um objetivo simples, desvela uma série de elementos para pensarmos nos desdobramentos de uma aula de Educação Física na escola: que o fato de ter jogado vários jogos de basquete não Ihe garantiu a aprendizagem dos elementos constitutivos do jogo (como, por exemplo, os elementos técnico-táticos básicos dos esportes de invasão); que é preciso estimular a participação coletiva nos jogos, para que todos tenham a chance de ter experiências de sucesso com as práticas corporais; que há a necessidade de um planejamento em termos de progressão dos temas estruturadores desenvolvidos para potencializar os alunos a uma participação mais efetiva nas diferentes situações da aula. Esses são apenas alguns elementos que entendemos devam ser considerados em uma relação de ensino e aprendizagem (neste caso, dos esportes de invasão), algo que nos permite reafirmar a necessidade da adoção de um referencial curricular (com protagonismo e a partir da realidade escolar) para que os alunos possam se apropriar das manifestações culturais relacionadas ao corpo, ao se-movimentar, ao campo do lazer e à promoção da saúde, abordadas nas diferentes formas de "conhecer" na Educação Física escolar pois, do contrário, perderão parte do acervo cultural produzido pela humanidade em torno das práticas corporais (González e Fensterseifer, 2010). desejáveis, potencializando-os a estabelecerem uma relação mais lúcida com o mundo e a construirem suas próprias interpretações para os problemas do seu tempo, iluminados pelo conhecimento de natureza escolar, mas abertos para a pluralidade própria dos espaços públicos democráticos.

\section{REFERÊNCIAS}

Almeida, L. Fensterseifer, P. y Bracht, V. (2014). Experiência. In: González, F. J. e Fensterseifer, P. E. (orgs.). Dicionário crítico de educação física (3. ed., pp. 297-302). Ijuí: Ed. Unijuí.

Arendt, H. (2011). A crise na educação. En Entre o passado e o futuro (7. ed.). São Paulo: Perspectiva.

Bondía, J. (2002). Notas sobre a experiência e o saber da experiência. Revista Brasileira de Educação, Rio de Janeiro, 19, 20-28.

Brayner, F. (2008). Educação e republicanismo: experimentos arendtianos para uma educação melhor. Brasília: Liber Livro.

Costa, J. (1999). Razões públicas, emoções privadas. Rio de Janeiro: Rocco.

Flickinger, H. (2010). A caminho de uma pedagogia hermenêutica. Campinas, SP: Autores Associados.

Gadamer, H. (2008). Verdade e método I: traços fundamentais de uma hermenêutica filosófica Tradução $\mathrm{F}$. P. Meurer; revisão da tradução, E. P. Giachini, 10 ed.). Petrópolis, RJ: Vozes.

González, F. (2006). Sistema de classificação dos esportes. En Rezer, R. O fenômeno esportivo: ensaios crítico-reflexivos (pp. 111-121). Chapecó: Argos.

González, F. e Fensterseifer, P. (2009). Entre o "não mais" e o "ainda não": pensando saídas do não-lugar da ef escolar I. Cadernos de Formação RBCE, 9-24.

González, F. e Fensterseifer, P. (2010). Entre o "não mais" e o "ainda não": pensando saídas do não lugar da ef escolar II. Cadernos de Formação RBCE, 10-21.

González, F. e Fensterseifer, P. (2014). Dicionário crítico de educação física (3 ed.). Ijuí: Ed. Unijuí.

González, F. e Fraga, A. (2009). Referencial Curricular de Educação Física. En Rio Grande do Sul. Secretaria de Estado da Educação. Departamento Pedagógico. Referenciais Curriculares do Estado do Rio Grande do Sul: Linguagens, Códigos e suas Tecnologias. Porto Alegre: SE/DP, 2, 111-181. 
González, F. e Fraga, A. (2012). Afazeres da Educação Física na escola: planejar, ensinar, partilhar. Erechim: Edelbra.

González, F. e Schwengber, M. (2012). Práticas pedagógicas em educação física: espaço, tempo e corporeidade. Erechim: Edelbra.

Hermann, N. (2002). Hermenêutica e educação. Rio de Janeiro: DP\&A.

Hildebrandt-Stramann, R. (2001). Textos pedagógicos sobre o ensino da Educação Física. Ijuí: Unijuí.
Jay, M. (2009). Cantos de experiencia: variaciones modernas sobre un tema universal. Buenos Aires: Paidós.

Kunz, E. (2000). Transformação didático-pedagógica do esporte (4 ed.) Ijuí: Ed. Unijuí.

Sacristán, J. G. e Gómez, A. I. P. (1998). Compreender e transformar o ensino (4 ed.). Porto Alegre: Artmed.

São Paulo. (2008). Proposta curricular do estado de São Paulo. São Paulo: SEE. 